Louisiana State University

LSU Digital Commons

Faculty Publications

Department of Biological Sciences

$1-1-2005$

\title{
Marine radiations at small geographic scales: Speciation in neotropical reef gobies (Elacatinus)
}

\author{
Michael S. Taylor \\ Louisiana State University \\ Michael E. Hellberg \\ Louisiana State University
}

Follow this and additional works at: https://digitalcommons.Isu.edu/biosci_pubs

\section{Recommended Citation}

Taylor, M., \& Hellberg, M. (2005). Marine radiations at small geographic scales: Speciation in neotropical reef gobies (Elacatinus). Evolution, 59 (2), 374-385. https://doi.org/10.1111/j.0014-3820.2005.tb00996.x

This Article is brought to you for free and open access by the Department of Biological Sciences at LSU Digital Commons. It has been accepted for inclusion in Faculty Publications by an authorized administrator of LSU Digital Commons. For more information, please contact ir@lsu.edu. 


\title{
MARINE RADIATIONS AT SMALL GEOGRAPHIC SCALES: SPECIATION IN NEOTROPICAL REEF GOBIES (ELACATINUS)
}

\author{
Michael S. TaYlor ${ }^{1,2}$ And Michael E. Hellberg ${ }^{1,3}$ \\ ${ }^{1}$ Department of Biological Sciences, Louisiana State University, Baton Rouge, Louisiana 70803 \\ ${ }^{2}$ E-mail: mtayL22@lsu.edu \\ ${ }^{3}$ E-mail:mhellbe@lsu.edu
}

\begin{abstract}
Studies of speciation in the marine environment have historically compared broad-scale distributions and estimated larval dispersal potential to infer the geographic barriers responsible for allopatric speciation. However, many marine clades show high species diversity in geographically restricted areas where barriers are not obvious and estimated dispersal potential should bring many sister taxa into contact. Genetic differentiation at small (separation $<1000 \mathrm{~km}$ ) spatial scales could facilitate speciation by mechanisms other than the gradual accumulation of reproductive isolation during extended allopatry, such as ecological adaptation to local environmental conditions or the rapid evolution of genes tied to mate recognition, but the role of each of these possibilities has not been simultaneously explored for any species-rich marine taxon. Here, we develop a robust phylogenetic framework for 31 taxa from a species-rich group of Neotropical reef fishes (Gobiidae: Elacatinus) using $3230 \mathrm{bp}$ from one mitochondrial and two nuclear gene regions. We use this framework to explore the contribution of large- and small-scale geographic isolation, ecological differentiation, and coloration toward the formation and maintenance of species. Although species of Elacatinus occur on both sides of the Isthmus of Panama, no sister species are separated by this barrier. Instead, our results indicate that sister taxa occur within oceans. Sister taxa usually differ by coloration, and more distantly related sympatric species frequently differ by resource use. This suggests that some combination of coloration and ecological differences may facilitate assortative mating at range boundaries or in sympatry. Overall, speciation in Elacatinus is consistent with a model of recurring adaptive radiations in stages taking place at small geographic scales.
\end{abstract}

Key words._-Adaptive radiation, biogeography, Caribbean, phylogeny, reef fishes.

Received September 24, 2004. Accepted December 14, 2004.

Following Mayr (1942), much of the literature on speciation has focused on identifying geographical barriers that can facilitate allopatric speciation. This search has been especially protracted in the marine literature because geographic isolating barriers are rarely obvious. Populations separated by several thousands of kilometers have been thought to be interconnected by pelagic larval dispersal, and thus could become isolated only by extreme distances or by extrinsic barriers that prevented dispersal (Mayr 1954; Briggs 1973; Springer 1982; Benzie 1998). One prominent barrier is the Isthmus of Panama, which separates closely related tropical marine taxa in the Atlantic and Pacific oceans (Bermingham and Lessios 1993; Marko 2002; Fukami et al. 2004). Other barriers, such as the Eastern Pacific Barrier (Ekman 1953) and land masses that emerge during lowered sea levels (e.g., Grigg and Hey 1992; Benzie 1998; Barber et al. 2002), were typically inferred by comparison of distributions for taxa believed to be closely related.

The presence of comparatively few known geographic barriers in the ocean, combined with the dispersal potential of larvae, does little to explain endemic radiations in tropical regions such as the Caribbean Sea (e.g., Domeier 1994; Hastings 2000; Williams and Mounts 2003; Morrison et al. 2004). Furthermore, recent studies have found significant genetic structure, even reciprocal monophyly, at the scale of hundreds of kilometers (Planes et al. 2001; Riginos and Nachman 2001; Barber et al. 2002; Dawson et al. 2002; Taylor and Hellberg 2003), as well as sister taxa with sympatric distributions (Duffy 1996; Hellberg 1998; Collin 2003). The absence of obvious geographic barriers in these regions, coupled with evidence of larval retention rather than dispersal (Jones et al. 1999; Swearer et al. 1999; Taylor and Hellberg 2003), sug- gests that population divergence and speciation may sometimes be mediated by mechanisms other than prolonged, broad-scale allopatry. Changes in climatic conditions or shifting ocean currents may isolate populations for a period sufficient for populations to diverge (Valentine and Jablonski 1983). Selection acting on differential resource use at localized geographic scales may play an important role in the speciation process (Duffy 1996; Orr and Smith 1998). Alternatively, the rapid evolution of reproductive traits may also result in reproductive isolation (Endler and Basolo 1998; Palumbi 1998; Hellberg and Vacquier 1999; Masta and Maddison 2002).

The role of geographical isolation, ecological differentiation (e.g., differences in habitat or behavior), and mate recognition to the formation and maintenance of new species can be evaluated in the context of a robust phylogenetic framework. If species from different lineages share similar ecological and morphological traits but differ in geographic distributions, then classic allopatric speciation would be favored. Alternatively, if sympatric sister species differ ecologically, then differences due to resource competition may have contributed to speciation (Lynch 1989; Losos 1990). Such inferences assume that species distributions have remained unchanged since their formation; however, when comparative phylogenetic inferences are coupled with independent evidence, such as common geographic distribution among different groups of sister taxa, the interpretation of historical processes may be reliable (Losos and Glor 2003).

To assess the historical contributions of geography, ecology, and mate recognition as processes underlying speciation requires a suitable taxon. With nearly 2000 described species, gobies (Gobiidae) constitute the largest family of marine fish- 
TABle 1. List of species used in this study. Two additional species, Elacatinus (Elacatinus) tenox and E. (Tigrigobius) zebrella were not available. Color refers to the lateral stripe color for Atlantic species of subgenus Elacatinus.

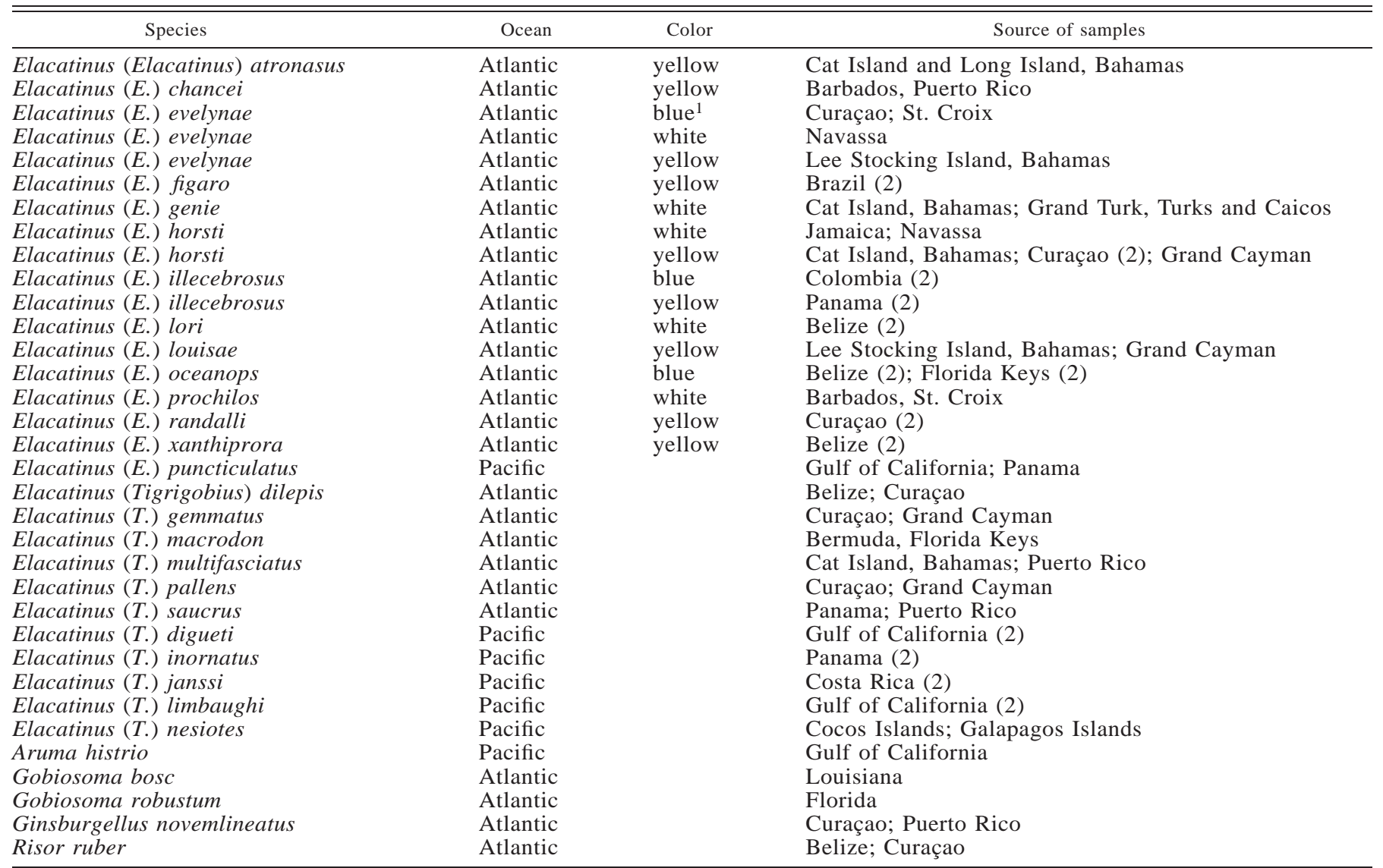

${ }^{1}$ Colin (1975) refers to this as the yellow-blue (YB) from in reference to the blue lateral stripe grading into yellow on the head. We refer to this as the blue form for simplicity.

es (Nelson 1994). In the Neotropical region, gobies are the most species-rich family of marine fishes (Robertson 1998). The Neotropical seven-spined gobies (Gobiosomatini) show particularly high levels of behavioral specializations and ecological differentiation, all of which have evolved over the last 40 million years (Rüber et al. 2003). Whether such specializations continue to influence patterns of speciation among recently formed taxa remains unknown.

Among the seven-spined gobies is the genus Elacatinus. This genus, with 27 nominal species (Table 1), is the most species-rich genus of fishes found on Neotropical coral reefs. (We follow Hoese [1971] and Eschmeyer [1998] by recognizing the genus Elacatinus with two subgenera, Tigrigobius and Elacatinus. These subgenera are equivalent to those applied by Rüber et al. [2003] to the genus Gobiosoma. We use sensu lato [s.l.] and sensu stricto [s.s.] to distinguish between the genus and subgenus Elacatinus, respectively.) The subgenus Tigrigobius contains 12 described species roughly equally divided between the Pacific and Atlantic Oceans. The subgenus Elacatinus has 15 described species, with only a single species found in the tropical eastern Pacific Ocean (Table 1). Several species of Elacatinus (s.s.) vary geographically by coloration but are otherwise morphologically indistinguishable (Colin 1975). Examining whether sister taxa of Elacatinus (s.1.) differ by geographical distribution, by ecological traits, by coloration differences, or by some combination of these will allow us to infer the mechanisms contributing to the origination of new species in this diverse and geographically restricted genus.

Here, we build a molecular phylogenetic framework using mitochondrial and nuclear markers to address mechanisms that potentially explain the observed diversity within the genus Elacatinus. Specifically, we address a series of related questions. First, did the Isthmus of Panama separate sister species of Elacatinus (s.1.)? If many sister species are so divided, then closure of the Isthmus would be implicated to have contributed greatly to species diversity in the genus. Second, if sister species occur together in the same ocean, do they have allopatric or sympatric distributions? Sympatric distributions for recently diverged sister species would suggest mechanisms other than gradual allopatric speciation. Alternatively, allopatric distributions would favor geographic speciation, albeit at smaller spatial scales than usually posited for marine taxa. Common distributional patterns for multiple species would suggest the presence of previously unrecognized geographic barriers. Finally, do sister taxa and sympatric taxa have consistent differences in ecological or behavioral traits, or in coloration? Such differences would suggest mechanisms that facilitate or maintain assortative mating at range boundaries and in sympatry. 


\section{Materials And Methods}

Two individuals from geographically distant populations were sampled for 21 of 29 ingroup taxa (including both species and genetically distinct color forms within species; Table 1); all other taxa were represented by two individuals sampled from the same population. We obtained samples of all currently described species and color forms in the genus except $E$. (E.) tenox, the white forms of E. illecebrosus and E. xanthiprora, and E. (T.) zebrella. Five putative outgroup taxa were selected based on previous morphological and molecular work (Van Tassell 1998; Rüber et al. 2003). In all, 67 individuals were analyzed. Specimens were collected and preserved in the field with $95-100 \%$ ethanol or a saturated salt-DMSO buffer (Amos and Hoelzel 1991). Specimens were subsequently stored in the laboratory at $-80^{\circ} \mathrm{C}$.

\section{DNA Amplification}

Total genomic DNA was extracted from muscle tissue with a Qiagen (Valencia, CA) DNA Mini Kit by following the manufacturer's instructions. The polymerase chain reaction (PCR) and the primers listed in the online supplementary table (available online only at http://dx.doi.org/10.1554/ 04-590.1.s1) were used to amplify protein-encoding regions of three genetic markers: mitochondrial cytochrome $b$ $(m t c y b)$, and nuclear recombination-activating gene 1 ( $r a g 1)$ and rhodopsin (rho). These three markers were chosen to provide independent estimates of phylogenetic relationships and to provide resolution at different hierarchical levels. Preliminary analyses of $m t c y b$ revealed short branch lengths at some internal nodes within the subgenus Elacatinus. To increase resolution at these nodes, an additional 512 bp were amplified from the two mitochondrial tRNAs (tRNA Glu and tRNA ${ }^{\text {Pro }}$ ) immediately following $m t c y b$ and the $5^{\prime}$ region of the mitochondrial control region ( $m t c r$ ).

The PCR was performed on a PTC-200 (MJ Research, Watertown, MA) with the following conditions: $94^{\circ} \mathrm{C}$ for three minutes for initial denaturing, followed by 35 cycles of $94^{\circ} \mathrm{C}$ for $15 \mathrm{sec}, 48-58^{\circ} \mathrm{C}$ for $20 \mathrm{sec}$, and $72^{\circ} \mathrm{C}$ for $30-60$ sec, depending on the primers used. Resulting amplicons were purified with a Strataprep PCR Purification Kit (Stratagene, La Jolla, CA), then sequenced in both directions with the amplification primers and Big Dye Terminators (V2.0, Applied Biosystems, Foster City, CA) on an ABI 377 automated sequencer. All sequences are available from GenBank (AY846392-AY846631).

\section{Phylogenetic Analyses}

Sequences for each gene region were assembled and edited with Sequencher 3.0, then aligned with an Internet implementation of ClustalW (http://www2.ebi.ac.uk/clustalw/) set to default parameters. The resulting dataset was analyzed with both maximum likelihood (ML) and Bayesian analyses using PAUP* version 4.0b10 (Swofford 2000) and MrBayes 3.0b4 (Huelsenbeck 2000), respectively. Evolutionary models were inferred independently for each marker and for the combined dataset with the aid of MrModeltest (J. A. A. Nylander, pers. comm.), a simplified version of ModelTest (Posada and Crandall 1998) that selects evolutionary models of nucleotide substitution applicable by both PAUP* and MrBayes. For the $m t c y b$, ragl and combined generic analyses, the general time reversible (GTR) model with a proportion of invariant sites and gamma-distributed rate heterogeneity $(\mathrm{GTR}+\mathrm{I}+\Gamma)$ was selected; the rho and mtcr and the combined subgeneric datasets were modeled similarly, except with a single transition:transversion ratio $(\mathrm{HKY}+\mathrm{I}+\Gamma)$. The gamma distribution for each model was approximated with four discrete rate classes.

Each genetic marker was analyzed separately under both ML and Bayesian conditions and the appropriate model to determine whether they have similar phylogenetic histories and thus were suitable for combined analyses (Bull et al. 1993; Cunningham 1997). Confidence in combined analyses would be gained if individual markers showed evidence of similar phylogenetic histories. In contrast, questionable results would be obtained from a combined dataset if the markers showed different phylogenetic histories. We considered the markers to have different histories by the presence of strongly supported but conflicting clades between markers (Wiens 1998). We considered a clade to be strongly supported only if the clade had both ML bootstrap (MLB) support of $\geq 70 \%$ and Bayesian posterior probabilities (BPP) $\geq 95 \%$ (Leaché and Reeder 2002), as these two values often correspond in simulations (Hillis and Bull 1993; Suzuki et al. 2002). We required both values as evidence for strong support because Bayesian analyses can occasionally assign high posterior probability values to incorrect clades (Huelsenbeck et al. 2002), but such clades were much less likely to receive high bootstrap values (Douady et al. 2003). We considered the markers to have similar phylogenetic histories, and therefore be suitable for combined analyses, only in the absence of conflicting clades.

All ML phylogenies were estimated with heuristic searches with tree bisection-reconnection (TBR) branch swapping. A starting phylogeny was derived from the model and associated parameters estimated by MrModelTest. The optimal ML phylogeny was then derived with an iterative approach (Leaché and Reeder 2002). The initial phylogeny was used to re-estimate model parameters, which were then used to derive a new phylogeny. This process was repeated until ML scores converged on a single value, suggesting the most likely phylogenetic hypothesis had been found. Support for each clade was estimated by performing 100 MLB replicates for each dataset with the final estimated parameters for those data. Maximum likelihood analyses are computationally intensive, especially for large datasets. To conserve time, bootstrap analyses for the individual markers were performed with heuristic searches and nearest-neighbor interchange branch swapping on a starting neighbor-joining (NJ) tree. For the two combined datasets, a heuristic search and TBR branch swapping on a starting NJ tree was performed for 100 bootstrap replicates. Maximum likelihood bootstrapping of the combined dataset for the genus-level phylogeny took 4180 hours (nearly six months) of CPU time on a DEC Alpha 1 workstation (600 MHz EV67 21264A processor).

Bayesian analyses were performed by Markov chain Monte Carlo sampling for 1.2 million generations. Four metropoliscoupled chains were run simultaneously using uniform prior probabilities and appropriate model parameters estimated on 
a randomly generated starting phylogeny. Trees were sampled from the posterior-probability distribution once every 100 generations. Bayesian analyses were repeated five times for each dataset to reduce chances of selecting a local but not global optimum. All parameters were plotted to ensure each had reached stationarity and to determine the appropriate burn-in period. Burn-in occurred within the first 100,000 generations; we conservatively discarded the first 200,000 generations (2000 trees). The 10,000 sampled trees (after burnin) from each of the five independent runs were combined to determine final posterior probabilities.

Comparisons between alternative phylogenetic topologies were analyzed a posteriori with the Shimodaira-Hasegawa (SH) test (Shimodaira and Hasegawa 1999) and 100,000 resampling estimated log-likelihood approximated bootstrap replicates as implemented in PAUP* (Swofford 2000). Associations between discrete color and ecological character states were tested with the concentrated changes test (Maddison 1990), as implemented in MacClade 4.06 (Maddison and Maddison 2003).

\section{RESUlts}

Sequences resulting from PCR amplification were trimmed to exclude ambiguous reads at each end, which yielded 1140 bp for $m t c y b, 1290 \mathrm{bp}$ for ragl, and $800 \mathrm{bp}$ for rho, for a total of $3230 \mathrm{bp}$ for all individuals. Additionally, $143 \mathrm{bp}$ were amplified for the two tRNAs (144 bp for E. puncticulatus) and 357-366 bp of mtcr were amplified for all members of the subgenus Elacatinus, except for a single individual of $E$. xanthiprora, for which mtcr could not be amplified. This individual was excluded from all subgeneric analyses. A single putative amino acid deletion (three nucleotides) was observed in $m t c y b$ for both individuals of E. dilepis; no other indels were observed in $m t c y b$, ragl, or rho for any species. A single putative nucleotide insertion was observed in tRNA ${ }^{\text {Pro }}$ for $E$. puncticulatus. Several indels were observed in mtcr. Nucleotide positions containing indels were globally excluded from all phylogenetic analyses. Introns were absent from the sequenced regions of ragl and rho. Average genetic distances for each marker for representative taxonomic pairs are provided in Table 2.

We found no evidence for significant topological conflict among the three markers for both ML (Fig. 1) and Bayesian (topologies not shown) analyses. Although differences for some clades are apparent among markers, none of the conflicting clades have strong support for both MLB and BPP. Most topological discrepancies are between $m t c y b$ and the two nuclear markers. For example, the separate ragl and rho phylogenies both place E. gemmatus in a clade with E. pallens and $R$. ruber, with $100 \%$ support for both MLB and BPP. In contrast, mtcyb places E. gemmatus basal to the Tigrigobius and Elacatinus (s.s.) clades with $100 \%$ BPP but with less than $<50 \%$ MLB (Fig. 1). Given the lack of significant conflict, we concluded that the three genetic markers had a common phylogenetic history and were suitable for combined analyses (Bull et al. 1993; Cunningham 1997).

The ML phylogeny estimated from the combined dataset of $m t c y b, r a g l$, and rho does not support the monophyly of the genus (Fig. 2). The topology obtained from Bayesian analysis is identical (not shown). Analyses with unweighted and weighted maximum parsimony and parsimony bootstrap (100 replicates) also did not differ qualitatively from ML and Bayesian analyses (data not shown). Tigrigobius, as currently recognized (Böhlke and Robins 1968; Hoese 1971), is a polyphyletic grouping consisting of two clades. One of these clades consists of three Atlantic species (E. macrodon, E. saucrus, and E. dilepis; hereafter, the Tigrigobius clade sensu Rüber et al. 2003) and is sister to Elacatinus (s.s.) (Fig. 2). The Tigrigobius clade is strongly supported with 100\% MLB and BPP support. The second, more species-rich clade (supported by $90 \%$ MLB and $100 \%$ BPP support) consists of the remaining Atlantic species, all of the Pacific species, and two putative outgroup taxa, Ginsburgellus novemlineatus and Risor ruber (Fig. 2; hereafter, the Risor clade sensu Rüber et al. 2003). In addition to Ginsburgellus and Risor, Rüber et al. (2003) found that Evermannichthys spongicola (a species not sampled here) also fell within the Risor clade. Elacatinus (s.s.) is recovered as a monophyletic group by the analysis

TABLE 2. Uncorrected pairwise distances between representative systematic groups (Fig. 2) for the four genetic markers used in this study. A single letter after a species name indicates blue (b), yellow (y), or white (w) lateral stripe color, as appropriate.

\begin{tabular}{|c|c|c|c|c|}
\hline & $m t c y b$ & $m t c r$ & rag1 & rho \\
\hline \multicolumn{5}{|l|}{ Sister taxa } \\
\hline Elacatinus evelynae (b)/E. evelynae (w) & 0.0149 & 0.0417 & 0.0090 & 0.0000 \\
\hline E. illecebrosus (b)/E. illecebrosus (y) & 0.0211 & 0.0279 & 0.0047 & 0.0000 \\
\hline E. horsti $(\mathrm{y}) / E$. horsti $(\mathrm{w})$ & 0.0265 & 0.0590 & 0.0029 & 0.0019 \\
\hline E. macrodon/E. saucrus & 0.1182 & - & 0.0062 & 0.0081 \\
\hline E. inornatus/E. nesiotes & 0.0026 & - & 0.0004 & 0.0013 \\
\hline \multicolumn{5}{|l|}{ Subgenera $^{1}$} \\
\hline Elacatinus (s.s.)/Tigrigobius (s.1.) & 0.2120 & - & 0.0485 & 0.0286 \\
\hline \multicolumn{5}{|l|}{ Outgroup $^{1}$} \\
\hline Ingroup/outgroup & 0.2171 & - & 0.0824 & 0.0498 \\
\hline
\end{tabular}

${ }^{1}$ Subgenus Tigrigobius (s.1.) and ingroup both include all members of the Tigrigobius and Risor clades as defined in the text, including Risor ruber and Ginsburgellus novemlineatus (for details see text and Fig. 2). 

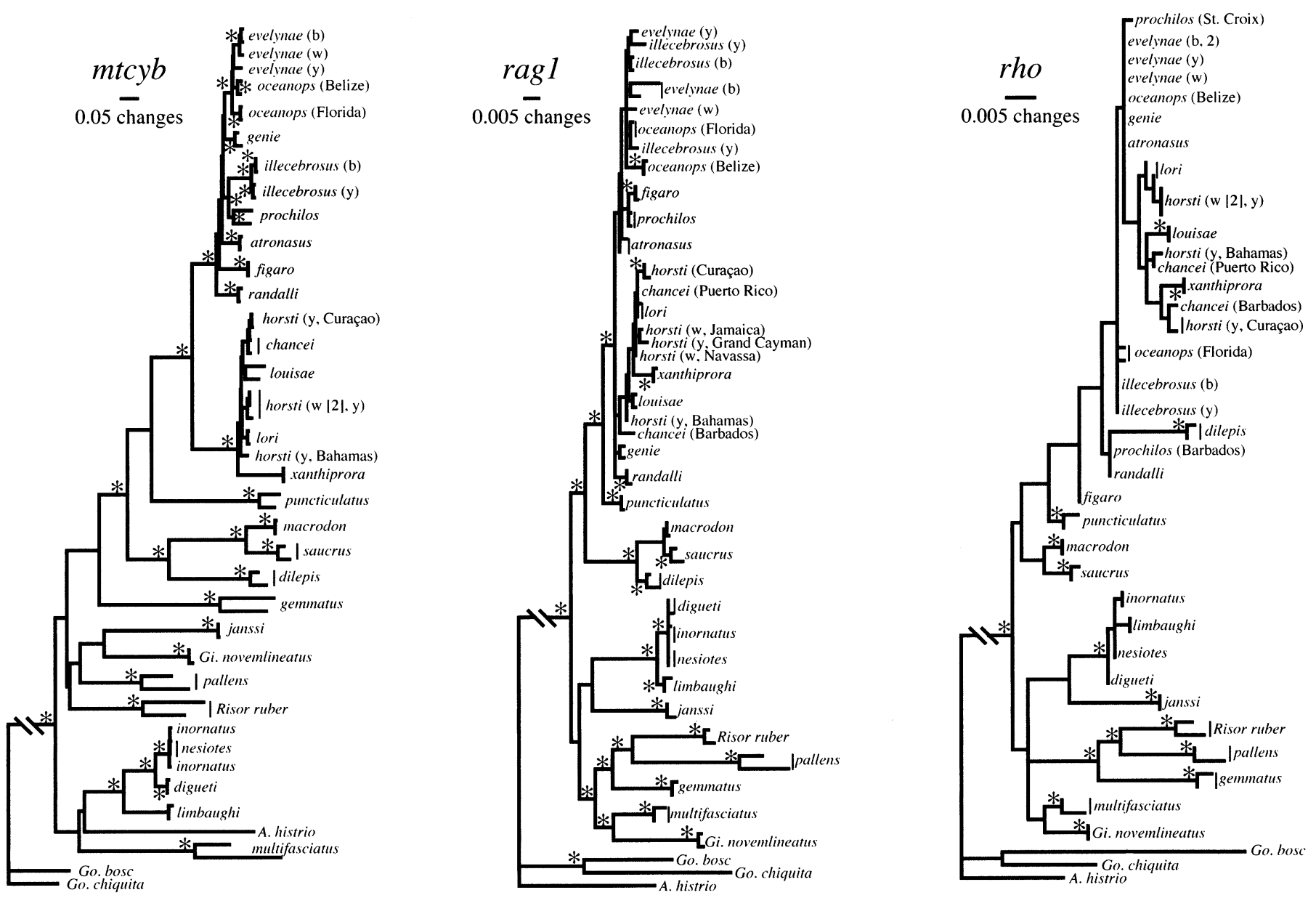

FIG. 1. Maximum likelihood phylogenies for the genus Elacatinus derived from three independent markers: mtcyb, rag1, and rho. A single letter after a species name indicates blue (b), yellow (y), or white (w) lateral stripe color, as appropriate. The number two indicates where two identical sequences share a branch tip. Population name is indicated for species that do not cluster together. Asterisks indicate strongly supported branches, with both maximum likelihood (ML) bootstrap proportions $\geq 70 \%$ and Bayesian posterior probabilities $\geq 95 \%$. None of the conflicting nodes are supported by high ML bootstrap and Bayesian posterior probabilities.

of the mtcyb, ragl, and rho dataset (Fig. 2), and with the addition of $m t c r$ and the two tRNAs (Fig. 3). The Bayesian phylogeny was again identical (not shown). The monophyly of Elacatinus (s.s.) is robust, with 100\% support from both MLB and BPP. The Atlantic radiation in this subgenus is also monophyletic (100\% MLB and BPP), with the single Pacific species, E. puncticulatus, recovered basal to the Atlantic species (Fig 3). Although taxonomic revision of the genus Elacatinus appears necessary, current taxonomic alignment does not affect the conclusions drawn here.

\section{Geography}

Only two splits are associated with the Isthmus of Panama (Fig. 2). The first divides the Risor clade into Atlantic and Pacific subclades. Each subclade is supported by $75 \%$ MLB and $100 \%$ BPP. The second split, separating the basal $E$. puncticulatus from the Atlantic species of Elacatinus (s.s.), has maximum support of $100 \%$ for both analyses. No sister taxa are sundered by the Isthmus of Panama.

Instead, sister taxa occur within the same ocean (Fig. 2), with the degree of geographic overlap between sister taxa varying among the three major clades. Most sister species in the Tigrigobius and Risor clades overlap geographically. Within the Tigrigobius clade, E. macrodon is largely allopatric with respect to $E$. saucrus and E. dilepis, which have primarily a Bahamian and Caribbean distribution (based on museum collection records, data not shown). However, $E$. macrodon has been collected as far south as Grenada (Böhlke and Robins 1968), which overlaps the range of the other two species. Elacatinus saucrus and E. dilepis have primarily southeastern and northwestern Caribbean distributions, respectively, but may have some degree of overlap because both have been collected from the Bahamas, Jamaica, Haiti, and the southern Lesser Antilles. In comparison, the five species that comprise the Atlantic Risor subclade (Fig. 2) are broadly sympatric across the Bahamas and Caribbean Sea. For the Pacific Risor subclade, the range of E. digueti overlaps all species in this group except for E. nesiotes, which is endemic to the Galapagos and Cocos islands. The nominal sister taxa E. nesiotes and E. inornatus are allopatrically distributed, but whether these two species are taxonomically distinct from E. digueti is debated (Bussing 1990; Hoese and Reader 2001). 


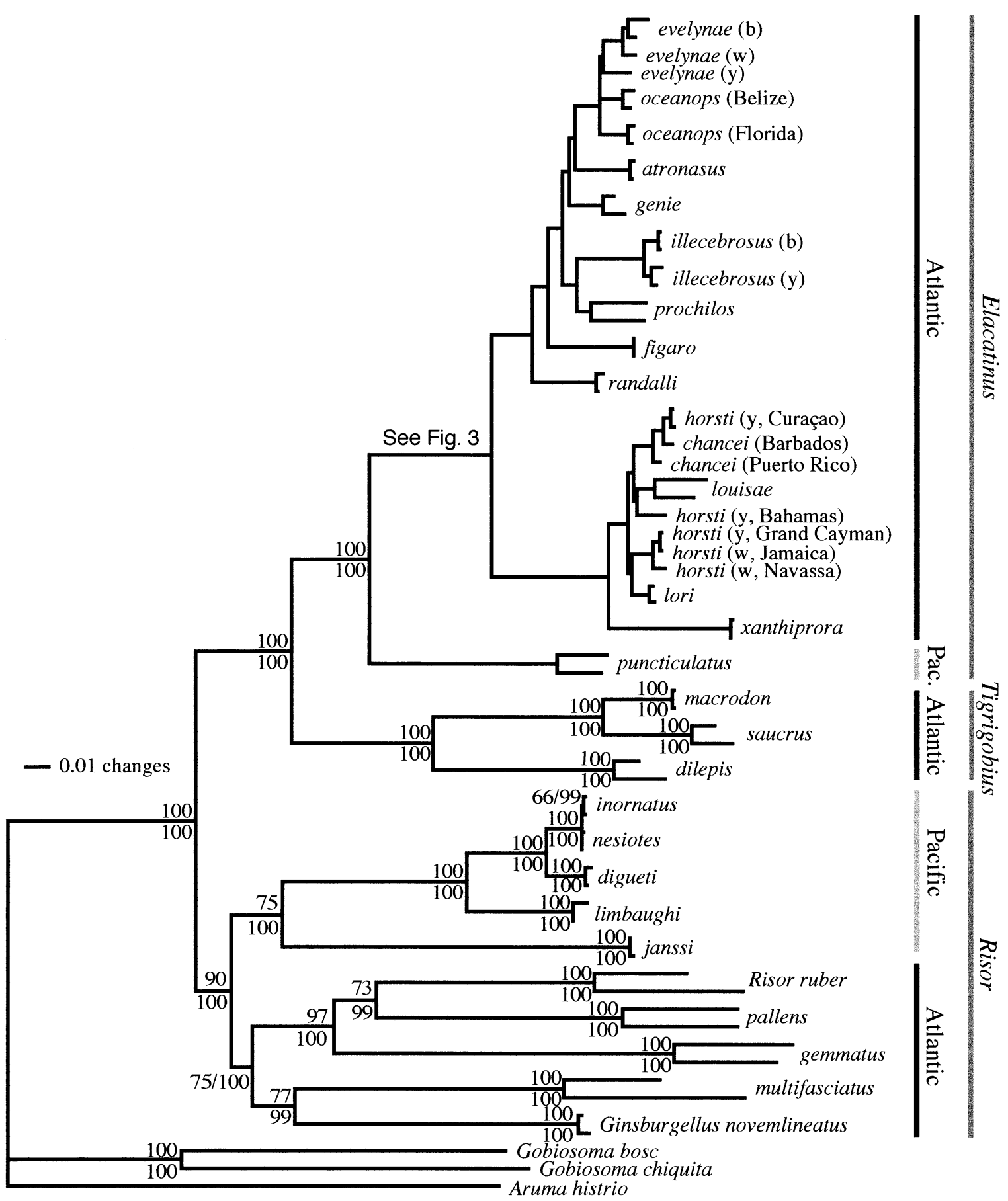

FIG. 2. Maximum likelihood (ML) phylogeny (GTR $+\mathrm{I}+\Gamma$ ) for the combined mtcyb, ragl, and rho dataset for the genus Elacatinus. Values above the branch or left of a slash are nonparametric ML bootstrap proportions. Values below the branch or right of a slash are Bayesian posterior probabilities. Support values for the subgenus Elacatinus are shown in Figure 3. Ocean basins and clades are indicated by vertical bars. The Tigrigobius and Risor clades together comprise the subgenus Tigrigobius as presently defined. See text for details.

The limited divergence $(0.1-0.2 \%$ uncorrected pairwise distance) that we found between our representatives of these taxa suggests they are very close, but our limited sampling cannot ascertain their species status.

In contrast to the two other clades, many sister taxa of Elacatinus (s.s.) are allopatrically distributed. For example, the three color forms of E. evelynae form a well-supported clade (91\% MLB, $98 \%$ BPP; Fig. 3) and are allopatrically distributed across the Bahamas and Caribbean (Colin 1975; Taylor and Hellberg 2003). In turn, this clade is sister to $E$. oceanops (99\% MLB, 100\% BPP; Fig. 3), which is allopatric with respect to E. evelynae (Colin 1975). A similar distributional relationship is found for E. prochilos and the color forms of E. illecebrosus, for E. chancei, E. lori, and the color forms of E. horsti (Fig. 2; Colin 1975). A white form is also known for E. xanthiprora (Colin 1975) but it was not obtained 


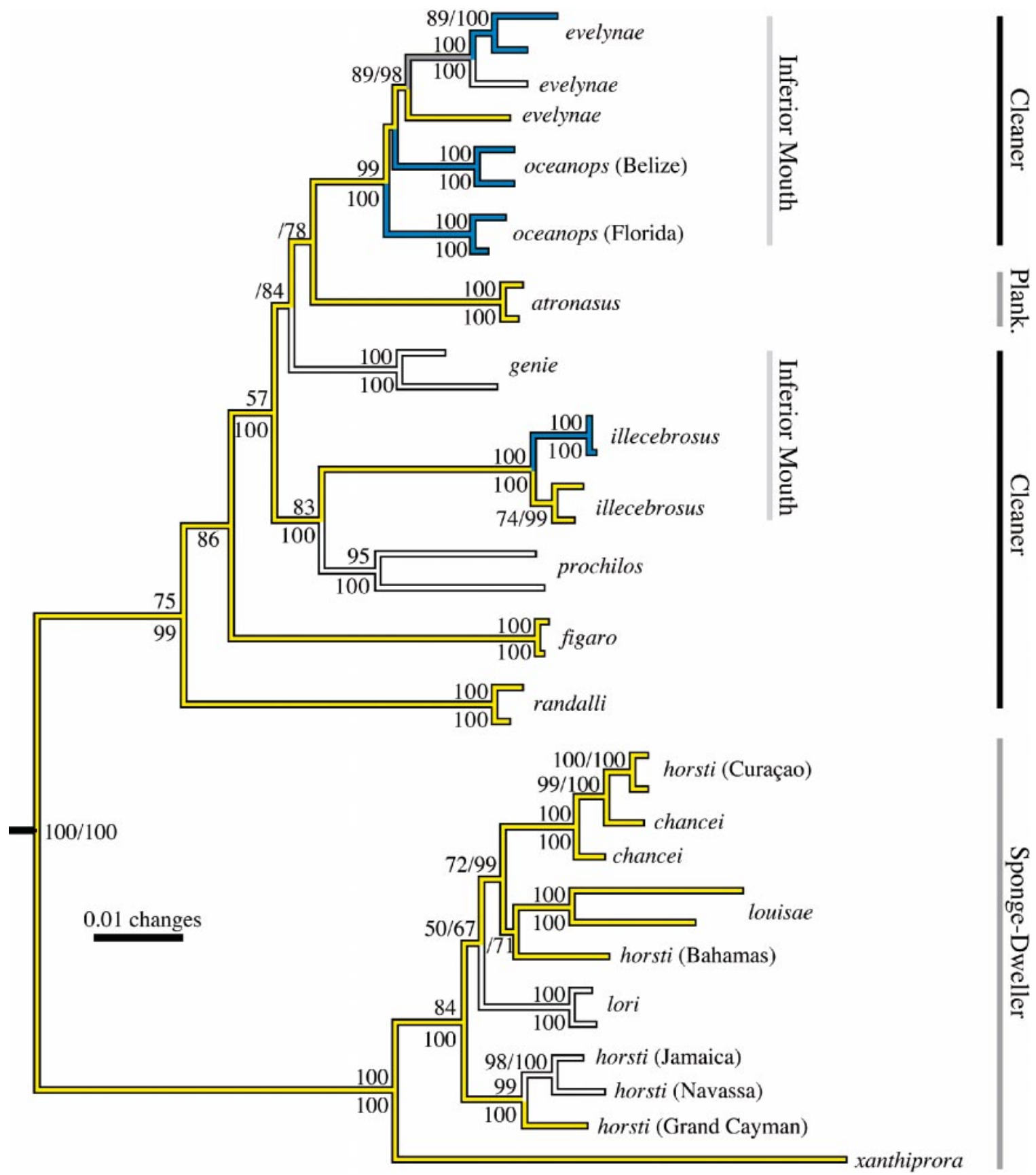

FIG. 3. Maximum likelihood phylogeny $(\mathrm{HKY}+\mathrm{I}+\Gamma)$ for the combined $m t c y b$, mtcr, two tRNAs, ragl, and rho dataset for Atlantic species of subgenus Elacatinus. Tree was rooted with E. puncticulatus, E. limbaughi, and Ginsburgellus novemlineatus. Support values indicated on branches as for Figure 2. Ecological traits and mouth position are indicated by vertical bars. Plank., schooling zooplankton feeder. Only species with inferior mouths placed below and behind snout tip are indicated; remaining species have mouths at snout tip (see text for details). Branch color corresponds to lateral stripe color.

for this study. The two color forms of E. xanthiprora are also apparently allopatrically distributed (Colin 1975).

\section{Habitat and Behavior}

Fully resolved sister taxa in Elacatinus (s.s.) all share similar ecological traits (Fig. 3). Sponge-dwelling (100\% MBL and BPP) and cleaning behaviors (77\% MLB, 99\% BPP) are monophyletic clades (Fig. 3), which confirm earlier findings based on more limited taxon sampling by Rüber et al. (2003). The sole plankton-feeding species, E. atronasus, falls within the cleaner clade, although the node containing this species is not fully resolved (Fig. 3). The placement of E. atronasus as sister to a monophyletic clade of cleaners cannot be rejected (SH test, $P>0.05$ ).

Many sister species within the Risor clade also exhibit similar ecological traits. All species within the Pacific sub- 


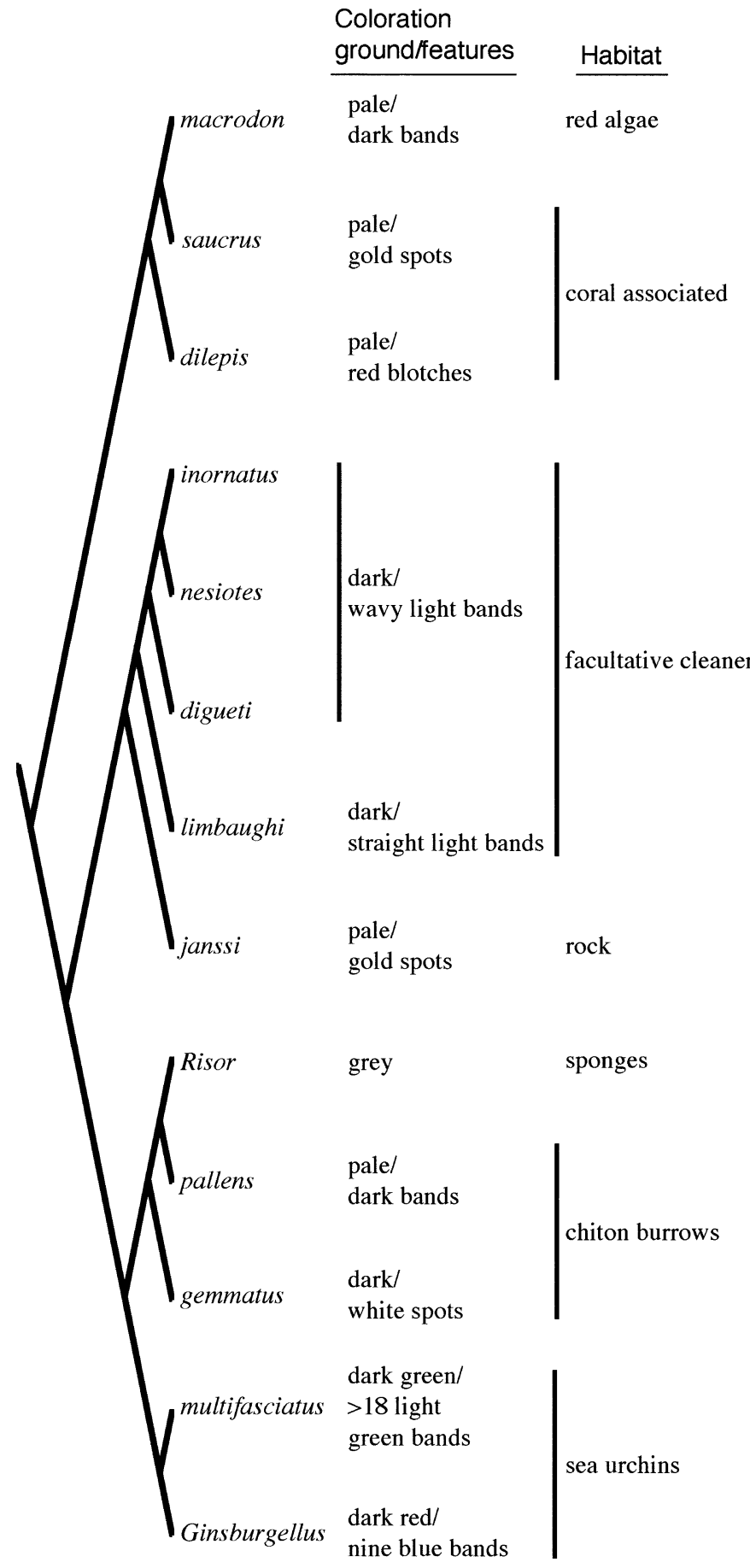

FIG. 4. Coloration and ecological traits of species belonging to the Tigrigobius and Risor clades. Phylogenetic relationships drawn from Figure 2. Coloration is given as body ground/features. Shared ecological traits indicated by vertical bars.

clade (Fig. 4) are facultative cleaners except E. janssi, which is associated with sandy and rocky substrates (Humann 1993; Allen and Robertson 1994). Within the Atlantic Risor subclade (Fig. 4), both G. novemlineatus and E. multifasciatus associate with sea urchins, primarily Echinometra (Erdman 1956; Smith 1957) and Diadema (M. S. Taylor, pers. obs.; Humann 1994). Elacatinus gemmatus and E. pallens can both be found in holes drilled by the boring chiton Choneplax lata (Taylor and Van Tassell 2002). Risor ruber and the putative sister taxon Evermannichthys (Rüber et al. 2003) are both obligate sponge dwellers.

\section{Coloration and Patterns}

Notably, within cleaner species belonging to Elacatinus (s.s.), sister taxa differ by the coloration of their lateral stripe (Fig. 3). The ancestral coloration appears to be yellow, with white and blue coloration evolving independently multiple times within the cleaners. No sister taxa share the derived white or blue coloration. White coloration has evolved at least twice in sponge-dwelling species (E. horsti and E. lori). If the unsampled white form of E. xanthiprora is sister to yellow form E. xanthiprora, then white coloration may have evolved three times in sponge-dwelling species. A monophyletic origin for each lateral stripe color within cleaners and within sponge-dwellers was strongly rejected ( $\mathrm{SH}$ test, $P \ll 0.001)$.

Coloration and patterns (e.g., vertical bands or spots) also distinguish between most sister species in the Tigrigobius and Atlantic Risor clades (Fig. 4). Most Pacific Risor species are similar, with subtle differences in coloration and pattern (Bussing 1990; Hoese and Reader 2001). Among Pacific Risor, E. janssi differs greatly from the other species by being spotted rather than banded (Bussing 1981).

\section{DisCUSSION}

The results of our combined analysis of three gene regions suggest that species of the genus Elacatinus (s.1.) fall into three clades (Fig. 2). Within each of these well-supported clades, sister taxa always occur to the same side of the Isthmus of Panama, which suggests that this potential isolating barrier has played no important role in the most recent bouts of species formation in this genus. Instead, sister taxa show strong differences both in microgeographic (within-ocean) distribution and in coloration, although the degree to which this holds varies among the three clades. Sister species also tend to be ecologically similar, but more distantly related species often differ ecologically (Figs. 3, 4). Ecological differentiation by macrohabitat, followed by diversification of behavior and microhabitat, has been previously demonstrated at higher hierarchical levels within the Neotropical gobies (Rüber et al. 2003), a pattern that fits a model of adaptive radiation in stages (Streelman and Danley 2003). This model also explains the phylogenetic pattern of Elacatinus (s.1.) demonstrated here. Together, this suggests that repeated radiations at small geographic scales, similar to that seen for terrestrial species on islands (Losos et al. 1998; Sato et al. 1999), may explain much of the gobiid diversity in the Neotropics.

\section{The Geographic Scale of Speciation}

That speciation in the marine environment may occur at much smaller geographic scales than previously believed has been suggested by many recent studies (Duffy 1996; Hellberg 1998; Riginos and Nachman 2001; Collin 2003; Taylor and Hellberg 2003; Mackenzie et al. 2004). Three lines of evi- 
dence support this conclusion. First, phylogenetic studies have revealed that sister taxa often have restricted distributions along the same coastline or occur sympatrically (Duffy 1996; Hellberg 1998; Marko 1998; Dawson et al. 2002), which may be a common pattern for species-rich taxa (Collin 2003). Second, experiments with chemical tags provide direct evidence that larval individuals may not disperse away from their natal populations (Jones et al. 1999; Swearer et al. 1999). Finally, significant population genetic structure at spatial scales $<1000$ kilometers provides indirect evidence for larval retention (Riginos and Nachman 2001; Barber et al. 2002; Taylor and Hellberg 2003).

Most species of Elacatinus (s.1.) are restricted to the Caribbean Sea and Bahamas (20 species total, not including Risor or Ginsburgellus), with only three to four species regularly found around Florida and in the Gulf of Mexico (Colin 1975; Humann 1994). Additionally, four nominal species of Elacatinus (s.s.) have multiple, geographically separated color forms (Colin 1975) that are also genetically distinct (Taylor and Hellberg 2003; M. S. Taylor and M. E. Hellberg, unpubl. data). This suggests that as many as 26 distinct taxa evolved within a geographic region spanning roughly 3000 $\mathrm{km}$ from Belize to Barbados and $3000 \mathrm{~km}$ from the northern coast of South America to the northern Bahamas.

Contained within this region, however, are more than 1000 islands and thousands of kilometers of coastline along Central and South America. The Bahamas alone contain over 700 islands spanning roughly $1225 \mathrm{~km}$ (Spalding et al. 2001). Most islands within the Bahamas and Caribbean are arranged in a stepping-stone arc enclosing this region, and are separated from neighboring islands by fewer than $100 \mathrm{~km}$. The close proximity of the islands, coupled with strong currents and dispersal of planktonic larvae, may in some species facilitate the rapid spread of unique haplotypes throughout the Caribbean and Bahamas (Shulman and Bermingham 1995), which could render distant populations genetically identical. Yet, despite the potential ability of larvae to disperse up to $500 \mathrm{~km}$ in a single generation (Taylor and Hellberg 2003), the high number of distinct Elacatinus (s.1.) taxa in this region suggests that gene flow among populations is minimal.

For example, E. evelynae has three allopatrically distributed color forms (yellow, blue, and white; Colin 1975) that are genetically distinct (Taylor and Hellberg 2003). A nearly identical distributional pattern (Colin 1975) is observed for a group containing $E$. chancei and genetically distinct color forms of E. horsti (M. S. Taylor and M. E. Hellberg, unpubl. data). The different taxa share common distributional boundaries in the central Bahamas and at Mona Passage between Puerto Rico and Hispaniola (Colin 1975). This suggests a common evolutionary history underlying differentiation of these taxa that may be influenced by proposed biogeographic breaks (Colin 1975, 2003; Baums et al. 2005; M. S. Taylor and M. E. Hellberg, unpubl. data). Yet, even within these regions, individuals from island populations are genetically distinct from other such populations, which suggests that larvae are not dispersing away from their natal populations (Taylor and Hellberg 2003). This lack of gene flow among populations may allow allopatric differentiation, and potentially speciation, to occur at geographic scales on the order of hundreds of kilometers.
A similar allopatric distribution is observed for the Tigrigobius clade (Fig. 2). Based on unpublished museum records, E. saucrus is found primarily in the southern Caribbean, $E$. dilepis in the northwestern Caribbean and Bahamas, and $E$. macrodon around Florida. Although all three species have been collected in close proximity to one another (e.g., western Hispaniola), the primarily nonoverlapping distributions of these species suggests speciation in allopatry at the scale of hundreds to thousands of kilometers. The allopatric distribution of sister taxa in Elacatinus (s.1.) suggests that geographic speciation at small spatial scales may be the most common mode of speciation in this genus.

Allopatric speciation at larger geographic scales, however, is evident for some species. Elacatinus figaro in the southwestern Atlantic Ocean may have been isolated from Caribbean species (Fig. 3) by the freshwater outflow of the Amazon and Orinoco rivers. This Amazon barrier has been implicated in the significant genetic differentiation and speciation of several coral reef fishes between the southwestern Atlantic Ocean and Caribbean Sea (Muss et al. 2001; Rocha et al. 2002; Rocha 2003). In the Pacific, E. nesiotes is endemic to the Galapagos and Cocos archipelagos and is separated by a vast expanse of open water from its mainland sister taxa of E. inornatus and E. digueti (Fig. 2). The Galapagos and Cocos archipelagos harbor a high percentage of gobiid endemics (Robertson 2001), suggesting their isolation generally proves beyond the dispersal ability of gobiid larvae.

\section{Radiation in Stages: Ecology and Color}

The rate at which allopatric populations give rise to new species may be enhanced by ecological differentiation and color-based mate choice (Turner and Burrows 1995; Allender et al. 2003; McKinnon et al. 2004). Both ecological and coloration differences have been implicated as forces that drive different stages of adaptive radiations (Streelman and Danley 2003). This evolutionary model predicts that divergence during adaptive radiations occurs in three intertwined stages: divergence by habitat, by morphological characters associated with trophic resource utilization, and by sensory communication. The order of these steps and the degree of diversification within each stage may vary among different taxa (Streelman and Danley 2003); however, this overall pattern of radiation has been observed for tropical marine fishes (Streelman et al. 2002; Rüber et al. 2003).

Speciation in Elacatinus (s.1.) appears to match the pattern of a staged adaptive radiation. Among Elacatinus (s.s.), an initial ecological divergence in habitat occurred between cleaners and sponge-dwellers (Fig. 3). Subsequent stages of diversification appear to be based on color and morphology. Diversification by color is most notable among cleaner species but color changes are evident in both clades, while morphological changes in mouth position have occurred among cleaner species (Fig. 3). Many cleaners (and all sponge-dwellers), have terminal mouths positioned at the tip of the snout, but E. evelynae, E. oceanops, E. genie, and E. illecebrosus all have mouths placed inferiorly well below and behind the tip of the snout (Böhlke and Robins 1968). As a result, these four species have been treated previously as a complex of closely related species (Böhlke and Robins 1968; Colin 
1975); however, a monophyletic origin for inferior mouths is not supported by our molecular data ( $\mathrm{SH}$ test, $P<0.05$ ).

A morphological change to an inferior mouth position is significantly associated with a change to a blue lateral stripe color (concentrated changes test, $P<0.05$ ). These associated morphological and coloration changes may be connected with cleaning behavior. The spectral reflectance of the blue lateral stripe of E. oceanops is similar to that of the Indo-Pacific cleaner wrasses and distinct from blues of most other reef fishes (Marshall 2000). The change to inferior mouth position may confer an advantage by facilitating removal of parasites from host fishes. Although speculative, this evidence suggests that cleaning behavior may in part be responsible for diversification of Elacatinus (s.s.).

The staged pattern of adaptive radiation is also evident for the Risor and Tigrigobius clades. Initial divergence again appears to be associated with ecological divergence (Fig. 4). Among Pacific Risor, initial divergence is between the rockdwelling $E$. janssi and the remaining facultative cleaners. The facultative cleaners then differ by color pattern, although the differences are subtle for E. inornatus, E. nesiotes, and $E$. digueti (Bussing 1990; Hoese and Reader 2001). Among the Atlantic Risor species, initial divergence appears to be between urchin-associated species and those associated with chiton burrows. This is followed by another habitat shift to obligate sponge dwelling for $R$. ruber. Although Figure 4 suggests $E$. pallens and $R$. ruber are sister species that differ by habitat, other evidence suggests that $R$. ruber is sister to Evermannichthys spongicola (Rüber et al. 2003), another obligate sponge dweller not included in this study. Habitat divergence is subsequently followed by divergence in color (between E. gemmatus, and E. pallens; Fig. 4) or morphology (between short, stout $R$. ruber and long, slender E. spongicola). For Tigrigobius, initial divergence among species appears to be by color patterns, then by habitat, between $E$. macrodon and E. saucrus (Fig. 4).

Habitat and coloration differences in Elacatinus (s.1.) may facilitate assortative mating. Similarly colored sympatric sponge-dwelling species segregate by depth (Colin 1975), which could help maintain reproductive isolation. Geographic isolation between allopatric, genetically distinct color forms of cleaner Elacatinus (s.s.) could be enforced by host recognition of cleaners. If cleaner goby coloration serves as a recognition cue for host fishes, then a differently colored goby may be perceived by the host as prey rather than as a cleaner, which would select strongly against immigrants with different lateral stripe colors (Palumbi and Warner 2003). We consider this scenario unlikely, however. First, most areas of the Caribbean harbor at least two sympatric cleaner Elacatinus (s.s.), each with a different lateral stripe color, and both of which may be observed simultaneously cleaning the same host fish (Colin 1975; Whiteman and Côté 2002). Second, as noted previously, some sponge-dwelling species share common boundaries with cleaner species, but sponge dwellers should not be constrained by host recognition. Thus, the allopatric distributions of color forms are more likely explained by larval retention and biogeographic barriers (M. S. Taylor and M. E. Hellberg, unpubl. data) rather than host selection based on color differences. Coloration differences, however, may facilitate mate recognition among both sym- patric cleaner species and differently colored individuals that transgress biogeographic breaks.

Color differences between sympatric Atlantic Risor taxa are also evident. Elacatinus gemmatus and E. pallens are frequently found in the same burrows (Taylor and Van Tassell 2002), but the former is dark-bodied and the latter is pale. Ginsburgellus novemlineatus and E. multifasciatus are both strongly banded, but differ greatly by color and the number of bands (Fig. 4). Although Tigrigobius species appear to be largely allopatric (see above), they occasionally occur sympatrically but differ by pattern, habitat, or both (Fig. 4). These ecological and coloration differences may simultaneously facilitate reproductive isolation between sister taxa (Domeier 1994; Seehausen et al. 1997; McMillan et al. 1999) and allow a greater number of species to coexist in the geographically compact region of the Neotropics.

\section{Conclusion}

Gobies are among the most species-rich taxa of all fishes (Nelson 1994) and are the largest component of Neotropical reef fishes (Robertson 1998). Although many Caribbean reef fishes appear to have large, genetically open populations (Shulman and Bermingham 1995; Rocha et al. 2002), our data suggest that, at least for Elacatinus (s.1.), speciation has occurred primarily in allopatry at small (separation $<1000$ $\mathrm{km}$ ) geographic scales. If gobiid larvae, as well as larvae of other small reef dwellers such as blennies and snapping shrimp, tend to remain near their natal reefs rather than disperse (Leis 1991; Duffy 1996), this mechanism alone may explain their relatively high species diversity. However, populations that remain closed for thousands of generations, as demonstrated for E. evelynae (Taylor and Hellberg 2003), may be able to adapt to local ecological conditions (Warner 1997; Grosberg and Cunningham 2000). Such ecological adaptation may facilitate rapid divergence between transiently allopatric populations and increase the potential for speciation (Turner and Burrows 1995; Duffy 1996; Rüber et al. 2003). Much of the historical evolution in the Neotropical seven-spined gobies, which includes Elacatinus (s.1.), is based on major shifts in macrohabitat, followed by diversification of behavior and microhabitat use (Rüber et al. 2003). Our results suggest that more recent bouts of speciation follow a similar pattern. Thus, repeated stages of adaptive radiations among allopatrically distributed sister taxa may explain much of the high diversity of gobies in the Neotropics.

\section{ACKNOWLEDGMENTS}

We thank L. Taylor, J. Van Tassell, J. L. Arreola, T. Austin, C. Baldwin, R. Bishop, F. Campos and the Organizacion para Estudios Tropicales, K. Cheney, B. Collette, I. Côté, M. Day, J. Garzon Ferreira, E. Haley and Sunset Divers Grand Cayman, S. Macia, J. McCosker, W. O. McMillan, J. Pawlik, S. Piontek, K. Rhode, D. R. Robertson, M. Robinson, D. Schrier, A. Siersma, C. Thacker, A. Tomba and the Cortez Club, C. Van Buuren, W. Von Lubbe, E. Whiteman, E. Wiley and the Kansas University Natural History Museum, J. Wilson, R/V Seward Johnson, R/V Sea Diver, and the Government of the Bahamas for assistance with obtaining specimens and tissue samples; P. Arbour-Reily, R. Brumfield, N. Crochet, H. Grif- 
fith, A. Leaché, and J. McGuire for technical assistance; and P. Colin and M. Noor for comments or discussions. This study was supported by grants from the American Museum of Natural History, the American Society of Ichthyology and Herpetology, and Sigma Xi (Louisiana State University Chapter) to MST, and National Science Foundation grants to MEH (DEB-0075382) and MST (Doctoral Dissertation Improvement Grant, DEB-0206632).

\section{Literature Cited}

Allen, G. R., and D. R. Robertson. 1994. Fishes of the tropical eastern Pacific. Univ. of Hawaii Press, Honolulu.

Allender, C. J., O. Seehausen, M. E. Knight, G. F. Turner, and N. Maclean. 2003. Divergent selection during speciation of Lake Malawi cichlid fishes inferred from parallel radiations in nuptial coloration. Proc. Natl. Acad. Sci. USA 100:14074-14079.

Amos, B., and A. R. Hoelzel. 1991. Long-term preservation of whale skin for DNA analysis. Rep. Int. Whal. Comm., Spec. Iss. No. 13:99-104.

Barber, P. H., S. R. Palumbi, M. V. Erdmann, and M. K. Moosa. 2002. Sharp genetic breaks among populations of Haptosquilla pulchella (Stomatopoda) indicate limits to larval transport: patterns, causes, and consequences. Mol. Ecol. 11:659-674.

Baums, I. B., M. W. Miller, and M. E. Hellberg. 2005. Regionally isolated populations of an imperiled Caribbean coral, Acropora palmata. Mol. Ecol. in press.

Benzie, J. A. H. 1998. Genetic structure of marine organisms and SE Asian biogeography. Pp. 197-209 in R. Hall and J. D. Holloway, eds. Biogeography and geological evolution of Southeast Asia. Backhuys Publishers, Leiden, The Netherlands.

Bermingham, E., and H. A. Lessios. 1993. Rate variation of protein and mitochondrial DNA evolution as revealed by sea urchins separated by the Isthmus of Panama. Proc. Natl. Acad. Sci. USA 90:2734-2738.

Böhlke, J. E., and C. R. Robins. 1968. Western Atlantic sevenspined gobies, with descriptions of ten new species and a new genus, and comments on Pacific relatives. Proc. Acad. Nat. Sci. Phila. 120:45-174.

Briggs, J. C. 1973. Operation of zoogeographic barriers. Syst. Zool. 23:248-256.

Bull, J. J., J. P. Huelsenbeck, C. W. Cunningham, D. L. Swofford, and P. J. Waddell. 1993. Partitioning and combining data in phylogenetic analysis. Syst. Biol. 42:384-397.

Bussing, W. A. 1981. Elacatinus janssi, a new gobiid fish from Costa Rica. Rev. Biol. Trop. 29:251-256.

- 1990. New species of gobiid fishes of the genera Lythrypnus, Elacatinus and Chriolepis from the eastern tropical Pacific. Rev. Biol. Trop. 38:99-118.

Colin, P. L. 1975. Neon gobies. T.F.H. Publications, Neptune City, NJ.

- 2003. Larvae retention: Genes or oceanography? Science 300:1657-1657.

Collin, R. 2003. Phylogenetic relationships among calyptraeid gastropods and their implications for the biogeography of marine speciation. Syst. Biol. 52:618-640.

Cunningham, C. W. 1997. Can three incongruence tests predict when data should be combined? Mol. Biol. Evol. 14:733-740.

Dawson, M. N., K. D. Louie, M. Barlow, D. K. Jacobs, and C. C. Swift. 2002. Comparative phylogeography of sympatric sister species, Clevelandia ios and Eucyclogobius newberryi (Teleostei, Gobiidae), across the California Transition Zone. Mol. Ecol. 11: 1065-1075.

Domeier, M. L. 1994. Speciation in the serranid fish Hypoplectrus. Bull. Mar. Sci. 54:103-141.

Douady, C. J., F. Delsuc, Y. Boucher, W. F. Doolittle, and E. J. P. Douzery. 2003. Comparison of Bayesian and maximum likelihood bootstrap measures of phylogenetic reliability. Mol. Biol. Evol. 20:248-254.

Duffy, J. E. 1996. Resource-associated population subdivision in a symbiotic coral-reef shrimp. Evolution 50:360-373.
Ekman, S. 1953. Zoogeography of the sea. Sidgwick and Jackson, London.

Endler, J. A., and A. L. Basolo. 1998. Sensory ecology, receiver biases and sexual selection. Trends Ecol. Evol. 13:415-420.

Erdman, D. S. 1956. Recent fish records from Puerto Rico. Bull. Mar. Sci. Gulf Carib. 6:315-340.

Eschmeyer, W. N. 1998. Catalog of fishes. Vol. 3. California Academy of Sciences, San Francisco, CA.

Fukami, H., A. F. Budd, G. Paulay, A. Solé-Cava, C. A. Chen, K. Iwao, and N. Knowlton. 2004. Conventional taxonomy obscures deep divergence between Pacific and Atlantic corals. Nature 427: 832-835.

Grigg, R. W., and R. Hey. 1992. Paleoceanography of the tropical eastern Pacific Ocean. Science 255:172-178.

Grosberg, R., and C. W. Cunningham. 2000. Genetic structure in the sea: from populations to communities. Pp. 61-84 in M. D. Bertness, S. D. Gaines, and M. E. Hay, eds. Marine community ecology. Sinauer Associates, Sunderland, MA.

Hastings, P. A. 2000. Biogeography of the tropical eastern Pacific: Distribution and phylogeny of chaenopsid fishes. Zool. J. Linn. Soc. 128:319-335.

Hellberg, M. E. 1998. Sympatric sea shells along the sea's shore: The geography of speciation in the marine gastropod Tegula. Evolution 52:1311-1324.

Hellberg, M. E., and V. D. Vacquier. 1999. Rapid evolution of fertilization selectivity and lysin cDNA sequences in teguline gastropods. Mol. Biol. Evol. 16:839-848.

Hillis, D. M., and J. J. Bull. 1993. An empirical test of bootstrapping as a method for assessing confidence in phylogenetic analysis. Syst. Biol. 42:182-192.

Hoese, D. F. 1971. A revision of the eastern Pacific species of the gobiid fish genus Gobiosoma, with a discussion of relationships of the genus. Ph.D. diss. University of California, San Diego, CA.

Hoese, D. F., and S. Reader. 2001. A preliminary review of the eastern Pacific species of Elacatinus (Perciformes: Gobiidae). Rev. Biol. Trop. 49:157-167.

Huelsenbeck, J. P. 2000. MrBayes: Bayesian inference of phylogeny. Distributed by the author. Department of Biology, University of Rochester, Rochester, NY.

Huelsenbeck, J. P., B. Larget, R. E. Miller, and F. Ronquist. 2002. Potential applications and pitfalls of Bayesian inference of phylogeny. Syst. Biol. 51:673-688.

Humann, P. 1993. Reef fish identification: Galapagos. New World Publications, Jacksonville, FL.

. 1994. Reef fish identification: Florida Caribbean Bahamas. New World Publications, Jacksonville, FL.

Jones, G. P., M. J. Milicich, M. J. Emslie, and C. Lunow. 1999. Self-recruitment in a coral reef fish population. Nature 402: 802-804.

Leaché, A. D., and T. W. Reeder. 2002. Molecular systematics of the eastern fence lizard (Sceloporus undulatus): a comparison of parsimony, likelihood, and Bayesian approaches. Syst. Biol. 51: 44-68.

Leis, J. M. 1991. The pelagic stage of reef fishes: The larval biology of coral reef fishes. Pp. 183-230 in P. F. Sale, ed. The ecology of fishes on coral reefs. Academic Press, San Diego, CA.

Losos, J. B. 1990. A phylogenetic analysis of character displacement in Caribbean Anolis lizards. Evolution 44:558-569.

Losos, J. B., and R. E. Glor. 2003. Phylogenetic comparative methods and the geography of speciation. Trends Ecol. Evol. 18: $220-227$.

Losos, J. B., T. R. Jackman, A. Larson, K. de Queiroz, and L. Rodríguez Schettino. 1998. Contingency and determination in replicated adaptive radiations of island lizards. Science 279: 2115-2118.

Lynch, J. D. 1989. The gauge of speciation: on the frequencies of modes of speciation. Pp. 527-553 in D. Otte and J. A. Endler, eds. Speciation and its consequences. Sinauer Associates, Sunderland, MA.

Mackenzie, J. B., P. L. Munday, B. L. Willis, D. J. Miller, and M. J. H. Van Oppen. 2004. Unexpected patterns of genetic struc- 
turing among locations but not colour morphs in Acropora nasuta (Cnidaria; Scleractinia). Mol. Ecol. 13:9-20.

Maddison, D. R., and W. P. Maddison. 2003. MacClade 4: Analysis of phylogeny and character evolution. Version 4.06. Sinauer Associates, Sunderland, MA

Maddison, W. P. 1990. A method for testing the correlated evolution of two binary characters: Are gains or losses concentrated on certain branches of a phylogenetic tree? Evolution 44:539-557.

Marko, P. B. 1998. Historical allopatry and the biogeography of speciation in the prosobranch snail genus Nucella. Evolution 52: 757-774.

—_ 2002. Fossil calibration of molecular clocks and the divergence times of geminate species pairs separated by the Isthmus of Panama. Mol. Biol. Evol. 19:2005-2021.

Marshall, N. J. 2000. The visual ecology of reef fish colours. Pp. 83-120 in Y. Espmark, T. Amundsen, and G. Rosenqvist, eds. Animal signals: Signalling and signal design in animal communications. Tapir Academic Press, Trondheim, Norway.

Masta, S. E., and W. P. Maddison. 2002. Sexual selection driving diversification in jumping spiders. Proc. Natl. Acad. Sci. USA 99:4442-4447.

Mayr, E. 1942. Systematics and the origin of species. Columbia Press, New York.

—_ 1954. Geographic speciation in tropical echinoids. Evolution 8:1-18.

McKinnon, J. S., S. Mori, B. K. Blackman, L. David, D. M. Kingsley, L. Jamieson, J. Chou, and D. Schluter. 2004. Evidence for ecology's role in speciation. Nature 429:294-298.

McMillan, W. O., L. A. Weigt, and S. R. Palumbi. 1999. Color pattern evolution, assortative mating, and genetic differentiation in brightly colored butterflyfishes (Chaetodontidae). Evolution 53:247-260.

Morrison, C. L., R. Rios, and J. E. Duffy. 2004. Phylogenetic evidence for an ancient rapid radiation of Caribbean sponge-dwelling snapping shrimps (Synalpheus). Mol. Phylogenet. Evol. 30: 563-581.

Muss, A., D. R. Robertson, C. A. Stepien, P. Wirtz, and B. W. Bowen. 2001. Phylogeography of Ophioblennius: The role of ocean currents and geography in reef fish evolution. Evolution 55:561-572.

Nelson, J. S. 1994. Fishes of the world. John Wiley and Sons, New York.

Orr, M. R., and T. B. Smith. 1998. Ecology and speciation. Trends Ecol. Evol. 13:502-506.

Palumbi, S. R. 1998. Species formation and the evolution of gamete recognition loci. Pp. 271-277 in D. J. Howard and S. H. Berlocher, eds. Endless forms: Species and speciation. Oxford Univ. Press, New York.

Palumbi, S. R., and R. R. Warner. 2003. Why gobies are like hobbits. Science 299:51-52.

Planes, S., P. J. Doherty, and G. Bernardi. 2001. Strong genetic divergence among populations of a marine fish with limited dispersal, Acanthochromis polyacanthus, within the Great Barrier Reef and the Coral Sea. Evolution 55:2263-2273.

Posada, D., and K. A. Crandall. 1998. Modeltest: testing the model of DNA substitution. Bioinformatics 14:817-818.

Riginos, C., and M. W. Nachman. 2001. Population subdivision in marine environments: The contributions of biogeography, geographical distance and discontinuous habitat to genetic differentiation in a blennioid fish, Axoclinus nigricaudus. Mol. Ecol. 10:1439-1453.

Robertson, D. R. 1998. Do coral-reef fish faunas have a distinctive taxonomic structure? Coral Reefs 17:179-186.

- 2001 . Population maintenance among tropical reef fishes: inferences from small island endemics. Proc. Natl. Acad. Sci. USA 98:5667-5670.

Rocha, L. A. 2003. Patterns of distribution and processes of speciation in Brazilian reef fishes. J. Biogeogr. 30:1161-1171.

Rocha, L. A., A. L. Bass, D. R. Robertson, and B. W. Bowen. 2002. Adult habitat preferences, larval dispersal, and the comparative phylogeography of three Atlantic surgeonfishes (Teleostei: Acanthuridae). Mol. Ecol. 11:243-252.

Rüber, L., J. L. Van Tassell, and R. Zardoya. 2003. Rapid speciation and ecological divergence in the American seven-spined gobies (Gobiidae, Gobiosomatini) inferred from a molecular phylogeny. Evolution 57:1584-1598.

Sato, A., C. O'hUigin, F. Figueroa, P. R. Grant, B. R. Grant, H. Tichy, and J. Klein. 1999. Phylogeny of Darwin's finches as revealed by mtDNA sequences. Proc. Natl. Acad. Sci. USA 96: 5101-5106.

Seehausen, O., J. J. M. van Alphen, and F. Witte. 1997. Cichlid fish diversity threatened by eutrophication that curbs sexual selection. Science 277:1808-1811.

Shimodaira, H., and M. Hasegawa. 1999. Multiple comparisons of log-likelihoods with applications to phylogenetic inference. Mol. Biol. Evol. 16:1114-1116.

Shulman, M. J., and E. Bermingham. 1995. Early life histories, ocean currents, and the population genetics of Caribbean reef fishes. Evolution 49:897-910.

Smith, C. L. 1957. Two new clinid blennies (Malacoctenus) from Puerto Rico. Occ. Pap. Mus. Zool. Univ. Mich. 585:1-15.

Spalding, M., C. Ravilious, and E. P. Green. 2001. World atlas of coral reefs. Univ. of California Press, Berkeley, CA.

Springer, V. G. 1982. Pacific plate biogeography, with special reference to shorefishes. Smithson. Contrib. Zool. 367:1-182.

Streelman, J. T., M. Alfaro, M. W. Westneat, D. R. Bellwood, and S. A. Karl. 2002. Evolutionary history of the parrotfishes: Biogeography, ecomorphology, and comparative diversity. Evolution 56:961-971.

Streelman, J. T., and P. D. Danley. 2003. The stages of vertebrate evolutionary radiation. Trends Ecol. Evol. 18:126-131.

Suzuki, Y., G. V. Glazko, and M. Nei. 2002. Overcredibility of molecular phylogenies obtained by Bayesian phylogenetics. Proc. Natl. Acad. Sci. USA 99:16138-16143.

Swearer, S. E., J. E. Caselle, D. W. Lea, and R. R. Warner. 1999. Larval retention and recruitment in an island population of a coral-reef fish. Nature 402:799-802.

Swofford, D. L. 2000. PAUP*. Phylogenetic analysis using parsimony (*and other methods). Version 4. Sinauer Associates, Sunderland, MA.

Taylor, M. S., and M. E. Hellberg. 2003. Genetic evidence for local retention of pelagic larvae in a Caribbean reef fish. Science 299: $107-109$.

Taylor, M. S., and J. L. Van Tassell. 2002. Observations on microhabitat utilization by three widely distributed Neotropical gobies of the genus Elacatinus. Copeia 2002:1134-1136.

Turner, G. F., and M. T. Burrows. 1995. A model of sympatric speciation by sexual selection. Proc. R. Soc. Lond. B 260: 287-292.

Valentine, J. W., and D. Jablonski. 1983. Speciation in the shallow sea: general patterns and biogeographic controls. Pp. 201-226 in R. W. Sims, J. H. Price, and P. E. S. Whalley, eds. Evolution, time and space: The emergence of the biosphere. Academic Press, New York.

Van Tassell, J. L. 1998. Phylogenetic relationships of species within the gobiid genus Gobiosoma sensu Böhlke and Robins (1968) with comments on their relationships to other genera in the tribe Gobiosomini. Ph.D. diss. City University of New York, New York.

Warner, R. R. 1997. Evolutionary ecology: how to reconcile pelagic dispersal with local adaptation. Coral Reefs 16:S115-S120.

Whiteman, E. A., and I. M. Côté. 2002. Cleaning activity of two Caribbean cleaning gobies: intra- and interspecific comparisons. J. Fish Biol. 60:1443-1458.

Wiens, J. J. 1998. Combining data sets with different phylogenetic histories. Syst. Biol. 47:568-581.

Williams, J. T., and J. H. Mounts. 2003. Descriptions of six new Caribbean fish species in the genus Starksia (Labrisomidae). Aqua 6:145-164.

Corresponding Editor: D. McHugh 